\title{
Production and purification of the phosphoprotein of Nipah virus in Escherichia coli for use in diagnostic assays.
}

\begin{abstract}
ABSTRACT Nipah Virus (NiV) is an emerging zoonotic paramyxovirus that can be fatal in humans and various types of animals. The phospho $(\mathrm{P})$ protein of $\mathrm{NiV}$ plays an important role in RNA synthesis, replication, and genome synthesis. In this study, the NiV P gene was cloned into a pTrcHis2-TOPO vector and the recombinant protein containing a His-tag was produced in Escherichia coli. SDS-PAGE and Western blot analysis using the anti-His antibody confirmed the protein expression. An optimization study of E. coli fermentation showed that the optimal cultivation temperature was $37 \hat{\mathrm{A}}^{\circ} \mathrm{C}$, while the optimal induction time for P protein expression was at $9 \mathrm{~h}$ with $1 \mathrm{mM}$ IPTG. Solubility analysis showed that E. coli cultivated at $37 \hat{\mathrm{A}}^{\circ} \mathrm{C}$ produced the highest fraction $(70 \%)$ of soluble $\mathrm{P}$ protein. The recombinant $\mathrm{P}$ protein was purified from clarified $\mathrm{E}$. coli lysate using an immobilized metal affinity chromatography (IMAC) technique to a purity of $92.67 \%$, with a purification factor of 11.58. The purified $\mathrm{P}$ protein strongly reacted with the anti-NiV swine sera collected during a NiV outbreak, suggesting its potential as a diagnostic reagent.
\end{abstract}

Keyword: Nipah virus; Phosphoprotein; IMAC; ELISA; Antigenicity; Diagnostic agent. 